\title{
New Begining...
}

The role of journal editor has become important in the wake of Academic medicine in Nepal. But most of the authors are in the dilemma of why should we get published and which journal? What should we publish? These are most important concern and more than that is "How to get a paper published?"1 For which a competent editorial board is a must to provide the most authentic literature to the community by ensuring journal's quality, indexing and timely publication.

International Committee of Medical Journal Editors has states as an editor of a journal is the person responsible for its entire content. Owners and editors of medical journals have a common endeavor-publication of a reliable, readable journal produced with due respect for the stated aims of the journal and for costs. Owners and editors, however, have different functions. Owners have the right to appoint and dismiss editors and to make important business decisions in which editors should be involved to the fullest extent possible. Editors must have full authority for determining the editorial content of the journal. The concept of editorial freedom should be resolutely defended by editors even to the extent of their placing their positions at stake. To secure this freedom in practice, the editor should have direct access to the highest level of ownership, not to a delegated manager. ${ }^{2}$

Committee on Publication Ethics states that editors must take final responsibility for everything in the publication they edit. Therefore, it is their duty to do their utmost to identify publication misconduct in submitted or published articles. ${ }^{3}$

The Nepal Medical Association (NMA), is a professional organization of all Nepalese doctors, who has lots of responsibilities towards Nepalese medical fraternity among them scientific publication is one of the most important aspect to raise the academic medicine in Nepal. The owner of Journal of Nepal Medical Association (JNMA) is NMA who first published it in the year of $1963 .{ }^{4}$ But it was indexed in the MedLine and other indexing bodies after more than four decades. Since 2005 it is adding literature to the world biomedical community through such indexing body and providing its content freely from its website. Beside this it has started promoting young doctors in the editorial body to keep up the pace with the rapidly changing medical literature and improved its infrastructure too. ${ }^{5}$

The contributors and editors are the two ends of a sea-saw if they perform their responsibility with purity a balance are maintained. The peer reviewers and readers are the close associates with it. The reality is that the either ends of the sea-saw have miles to go and tons to learn in the field of scientific manuscript preparation, publication and editing in the developing world. Same is for authors and peer reviewers.

If only JNMA manuscript format is checked of all articles submitted than more than half papers are rejected and if we consider about new scientific contribution of the articles then most of them would not find space in the journal. However, JNMA is acting as a mentor to the researcher and promoting them to work more in the academic medicine by helping them from all aspects. There are very few peer reviewers who give comments, criticisms, suggestions and recommendations. Many just put "accepted", "rejected", "accept with revision" or "accept with minor/major revision", without giving many valid points about their critical appraisal. So where do the loopholes lie? The medical journals are part and parcel of our professional activities and medical education rather than be just a part of an academic achievement. When someone have something to publish, it is absolutely necessary to choose appropriate journal as per the scientific content, read the journal, follow their manuscript preparation guidelines and submit. It needs a tremendous energy, hard work and time consuming but there is no short cut. If it is done, it will get a straightforward rejection letter which may be good because it can submitted in other journals without wasting much time but the fate will be the same if author doesn't take appropriate measures or the paper doesn't contribute sufficient enough! ${ }^{6}$ 
The editors have a very difficult situation in the developing countries like Nepal. The journals receive quite a less number of submissions with poor manuscript preparation and very few papers stand out to contribute to the scientific community. First, an editor most be competent enough to judge the quality of paper. Secondly, it is volunteer work especially in the JNMA. Thirdly, the editors have to play other equally important roles and bear responsibilities like promoting author for more writing. The editors have to be supportive, helpful and guide authors for their manuscript preparation, addressing peer reviewers' comments and encourage submitting the articles. ${ }^{7}$ The journals improve only after the editors, contributors, peer reviewers and readers are expert in their respective roles and supported by fraternity.

At present, we are in the zone of transition to start a new era of academic medicine in Nepal. One group is established, more experience and holds the key positions in the community while another is rapidly growing young medical community which is updated, smart, energetic and to faces the challenge of the competitive modern world. It has been realized by the JNMA and merged these two groups in the editorial board. ${ }^{5}$ The better outcome of the combination has been seen and realized by the medical fraternity.

As we come to the end of our tenure, this being last issue of current editorial board, there remains a lot to be done to go a long way which has to be carry out by the next editorial body. The first thing will be to have a dedicated team of experienced editors to ensure quality and further improvement in the journal and should maintain international standard. Secondly to carry out the planned activities of promoting scientific research and writing in the field of medicine and thirdly, to incorporate new and innovative activities as well as approaches such as author, peer reviewer and editorial training regularly. The last but not the least is to promote editors and providing incentive for their hard work because it has been seen that without incentive no work would be productive in the long run though it might seems fine in the beginning. JNMA editorial work is no more a volunteer job neither it can be done on that basis. The rules and regulation made long back has to be changed in terms of appointing new editorial body and regarding their incentive and promotion with the present situation. This is an expert work and should be employed on a professional basis. This is even more important in the context of Nepal where editors not only work at their professional level but also as a teacher and mentor to provide guidance, flexible and untiring support to the authors and medical fraternity in Nepal. The editorial independence must be unquestionable. ${ }^{8}$

\section{REFERENCES}

1. Lundberg GD. How to write a medical paper to get it publish in a good journal. MedGenMed 2005 Nov 4;7(4):36.

2. International Committee of Medical Journal Editors [Online]. 2008 Oct [cited 2008 Nov 25]; Available from: URL:http:/ / www.icmje.org/index.html\#editor

3. Committee on Publication Ethics [Online]. [cited 2008 Nov]. Avilable from: URL:http:// publicationethics.org/code-conduct

4. Journal of Nepal Medical Association 1963 Vol. 1, No. 1.

5. Research, publication and young doctors. J Nepal Med Assoc 2007 Jan-Mar;46(165):I-II.

6. Chernick V. How to get your paper rejected. Pediatr Pulmonol. 2008 Mar;43(3):220-3.

7. Marusić M, Marusić A. Good editorial practice: editors as educators. Croat Med J 2001;42:113-120.

8. Vogel M. Sacking of CMAJ editors. Lancet 2006 May 6:367(9521):1486. 